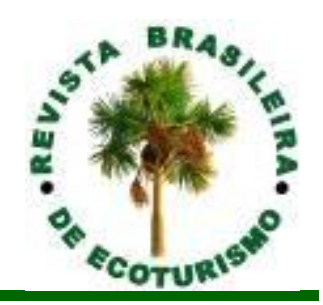

\title{
A Feira do Troca na comunidade de Olhos d'Água (GO): da afirmação cultural a apropriação pelo turismo
}

\section{The Fair Trade in Olhos d'Agua community (GO, Brazil): from the cultural affirmation to appropriation by tourism}

\author{
Edilene Américo Silva
}

\section{RESUMO}

Aqui são tecidas algumas considerações sobre a dinâmica socioespacial instalada na comunidade de Olhos d'Água, no município de Alexânia, por meio da Feira do Troca. Apresenta uma discussão sobre a contribuição deste evento na constituição da identidade local e a sua posterior apropriação pela atividade turística, mediante uma pesquisa bibliográfica conceitual e temática, observação e entrevistas. Como resultado apresenta-se uma problematização das transformações e persistências nas práticas socioespaciais da comunidade angulando a importância originária da Feira na afirmação cultural do lugar, o processo seguinte de "reinvenção" da Feira e sua crescente sujeição ao mercado turístico.

PALAVRAS-CHAVE: Feira do Troca; Identidade Local; Turismo.

\section{ABSTRACT}

Here are woven some thoughts on the socio-spatial dynamics installed in Olhos d'Agua community in the county of Alexânia, through Fair Trade. It presents a discussion on the contribution of this event in the constitution of local identity and its subsequent appropriation by tourism through a conceptual and thematic literature, observation and interviews. As a result presents a problematization of change and persistence in socio-spatial practices of community angling the originally importance from Fair on cultural affirmation of the place, the following process of "reinvention" of the Fair and its increasing liability to tourist market.

KEYWORDS: Fair Trade; Cultural Identity; Tourism. 


\section{O município de Alexânia}

Alexânia que está localizado na microrregião do Planalto Goiano com altitude média, aproximada, de 1.100 metros. As coordenadas da sede municipal são 16 04' 12" de latitude sul, e 48 31' 12" de Longitude W. Gr. O seu clima local tem características de clima tropical de altitude e a área administrativa limita-se com os municípios de Santo Antônio do Descoberto, Luziânia, Silvânia, Abadiânia e Corumbá de Goiás. O relevo local não apresenta nenhuma particularidade de destaque e é recortado pelos rios Corumbá, Areias e do Ouro (IBGE, 2014). O município em questão é relativamente jovem, criado por lei estadual no 4.919, de 14/11/1963, e é constituído pela sede municipal mais os distritos de Olhos d'Água e Rio do Ouro. Sua população total estimada é de 25.805 mil pessoas (IBGE, 2014).

Acredita-se que a localização geográfica, na borda do Eixo' Brasília-Goiânia (BR 060), coloque esse município como território privilegiado para onde convergem investimentos econômicos das esferas estadual e federal. O poder público local esclarece que "por muito tempo a economia de Alexânia era baseada apenas na agropecuária. Agora, o município está se tornando [...] um importante polo industrial, recebendo, cada vez mais, pequenos, médios e grandes empreendedores que acreditam e investem na região". Nesse sentido foi criado, em 2005, o Distrito Industrial de Alexânia, que somados ao recém-inaugurado Outlet Premium Brasília (2013) e a Schincariol - atual Brasil Kirin (2010), contribuem para os crescentes aumentos do PIB municipal. Segundo o IBGE (2014), este índice saltou de 50.183 mil (em 2000) para 327.857 mil (em 2010) e 350.273 mil (em 2011).

No contexto municipal, enquanto a sede se destaca pela dinâmica econômica, as expressões culturais de destaque, tem gênese na pacata e bucólica Olhos d'Água. A comunidade localiza-se a $14 \mathrm{~km}$ de distância do Eixo e, aos sentidos de quem nela chega pela primeira vez, parece que o tempo vivido pela população local é um tempo sem pressa, sem a correria comum da cidade grande.

\section{A gênese de Olhos d'Água}

Segundo dados do site da comunidade de Olhos d'Água ${ }^{2}$ e de informações obtidas junto à população local, o povoado surgiu de uma promessa religiosa, feita por uma moradora da região, de construir uma capela em homenagem a Santo Antônio de Pádua.

Em torno da pequena igreja, fundada em 1941, consolida-se o povoado de Santo Antônio de Olhos d’Água, em terras "doadas pelo fazendeiro Geminiano Ferreira de Queiroz" ${ }^{3}$ cuja família já possuía terras no local desde o final do século XIX. Segundo o Professor Armando, importante liderança comunitária,

quando ele e sua esposa aportaram, pela primeira vez, na comunidade depararam-se com uma realidade de extrema pobreza vivida pela maioria da população. As famílias, em sua maioria, viviam em moradias bem precárias e trabalhavam para o coronel Geminiano, proprietário das terras onde hoje está assentada a comunidade, em troca de um pouco de comida (entrevista realizada em julho/2014). 
As terras doadas foram repartidas pela igreja em pequenos lotes onde alguns foram repassados, sem custo, e outros foram vendidos, a quem quisesse ali se estabelecer. Assim, o período de 1910 a 1950 tem-se o início e a consolidação da comunidade.

O modelo de arquitetura das casas (atualmente em bom estado de conservação) veio pelas mãos dos mestres de construção de Corumbá de Goiás (município goiano vizinho), que conservaram as características arquitetônicas iguais as das antigas casas da região (datadas do século XIX). Assim, aos olhos do visitante, fica a impressão de ser Olhos d’Água mais antiga do que aparenta. As matérias-primas utilizadas foram, basicamente, adobe ${ }^{4}$, madeiras do Cerrado e telhas de barro, fabricadas pelos moradores.

Os homens que trabalhavam na comunidade plantavam milho, feijão, arroz e mandioca e mantinham pequenas criações. Além disso, associado as mulheres, produziam, para seu uso, utensílios de barro, como panelas, potes e artigos de tecelagem. O isolamento do povoado, associado à capacidade produtiva, contribuiu para que a população criasse um modo de vida próprio. Era autossuficiente na produção de gêneros alimentícios de primeira necessidade; fiava e tecia as próprias roupas e fazia os utensílios de que necessitava - gamelas, colheres de pau e cestas. O contato com outras comunidades se dava por intermédio de viajantes e mascates, que traziam para trocar o que ali não era encontrado. A esse respeito o Professor Armando diz que "a poucos metros da minha casa, existem vestígios da antiga estrada real que era caminho de tropeiros".

Nas longas viagens, em carros de boi, esses tropeiros compravam o excedente da produção local e traziam algumas pequenas encomendas especiais - como sapatos ou algum tecido fino -, que eram compradas pelas famílias mais abastadas de Olhos d'Água. O sal consumido pela comunidade era obtido no sertão de Goiás e de Minas Gerais. Assim, O início do povoamento da comunidade é marcado pelo momento político em que ela ainda pertencia, legalmente, ao município de Cocalzinho de Goiás que teve origem no século XIX - e que serviu de inspiração ao modelo arquitetônico de Olhos d’Água.

Neste cenário, vai-se construindo a identidade cultural da comunidade com seu espaço de reprodução. No bojo desse movimento, tem-se também instalada, uma dinâmica socioespacial que resulta e reflete na relação dos sujeitos sociais aí presentes, resultando na constituição territorial e no crescimento do sentido de pertencimento ao lugar, por estes sujeitos.

Nesse contexto, no ano de 1958, Olhos d'Água é elevada a município e consolida-se ainda mais, territorialmente, tendo na agricultura e artesanato os elementos propulsores da economia local. Entretanto, em 1961, esse movimento é abruptamente interrompido pela transferência das funções administrativa para outra área situada a $14 \mathrm{~km}$ dali. Essa nova cidade passa a ser chamada de Alexânia, imbuída da função de sede administrativa e política, e com a expectativa de trazer a modernidade visto que estava situada na borda da nova estrada - depois denominada BR 060 -, que ligaria as cidades de Brasília e Goiânia.

Desse modo, no período de 1961 até 1970, aproximadamente, a comunidade de Olhos d'Água vive um momento de 'estagnação' pela perda da força política. Esse fato traz reflexos também na organização comunitária. $E$ os arranjos produtivos locais (até então autossuficientes) sofrem rupturas levando à desarticulação da economia local. 
Entretanto, esse cenário começa a sofrer mudanças, positivas à desenvoltura da comunidade, a partir dos anos de 1971 a 1980 pela preparação e realização de algumas festas gestadas no âmbito da própria comunidade. Entre estes festejos é criada a Feira do Troca que, na prática, traz a (re)afirmação da comunidade por meio do retorno às suas origens. Através do artesanato é traçado o caminho que leva a comunidade a se reconhecer como peça importante na nova conjuntura política municipal. Que o futuro do município passa necessariamente pela sua gênese e que está reside na pacata Olhos d'Água. E voltar às origens conduz ao movimento de enxergar o lugar, a cultura alimentar, artesanal e religiosa. Demanda que os sujeitos conheçam a sua história para reviver os elementos identitários sob outro tempo.

E a Feira do Troca, paulatinamente, foi se constituindo como elemento propulsor que conduzia o coletivo a uma ação conjunta (produção para realização do evento) que, por sua vez, (res)significava o seu saber-fazer. Os conhecimentos ancestrais foram resgatados e reproduzidos pelas novas gerações que nesse movimento fortaleciam seu vínculo com o lugar e sua territorialidade.

\section{A Feira do Troca: elemento de afirmação da identidade local}

A graciosidade interiorana de local de Olhos d'Água sobressai de imediato aos olhos de quem nela chega. Embora o início do povoamento date da primeira metade do século XX, o padrão arquitetônico colonial serviu de inspiração para as primeiras edificações locais. Sobressai aos olhos de quem chega o bom estado de conservação das edificações, os tons coloridos das casas e a sua disposição espacial em torno de uma ampla área gramada e arborizada, que tem ao centro uma igreja e um cruzeiro.

Além da Feira do Troca, consideram-se também como marcos identitários a culinária representada pelo arroz-com-pequi; o artesanato em cerâmica, metal e pedra; as toalhas tecidas nos teares familiares - que são alimentados por fios produzidos a partir do algodão plantado e colhido pelos moradores; as bonecas de pano adornadas com roupas e cabelos coloridos; as peças em argila; e as imagens sacras - confeccionadas com a palha do milho produzido na própria comunidade. Acrescente-se a esses elementos, o povoado situar-se em um vale cujas terras são constituídas por solos escuros e densamente drenados por inúmeras nascentes recobertas por um Cerrado preservado.

Em conversas realizadas junto à comunidade identificou-se a Feira do Troca como a expressão cultural que está na lembrança imediata da população quando perguntada sobre qual evento melhor representa a história local.

"A 'Feira do Troca', que existe desde 1974, me lembra muito quando nós começamos a preparar uma festa só nossa. No começo era pequenininha, mas foi crescendo e a gente trabalhava vários meses pra organizar os produtos que a gente ia trocar. [...] A Feira é onde o da roça é trocado pelo da cidade" (Dona Nair, moradora de Olhos d'Água; julho/2014). 
Nas pesquisas bibliográficas, identificou-se que a Feira é citada como a atividade cultural mais conhecida no município. Possui força mobilizadora de turistas, de Brasília e de outros municípios goianos, que visitam a comunidade durante os três dias de realização das festividades.

Segundo dados do site da comunidade, a "primeira Feira do Troca aconteceu em dezembro de 1974, como parte de um projeto de arte-educação implantado pela professora Laís Aderne". Esta expressão se apresenta como um referencial, elemento identitário do próprio lugar e em escala municipal e estadual, como símbolo da cultura alexaniense e goiana.

A Feira contribui na definição da identidade da comunidade de Olhos d'Água e, ao mesmo tempo, é resultado da construção histórica dessa comunidade na constituição da paisagem e do seu território construído. Para Castells (apud LIMA, 2013, p. 55), "a construção de identidades forma-se a partir do que é fornecido pela história, geografia, biologia, instituições produtivas e reprodutivas, pela memória coletiva e por fantasias pessoais, pelos aparatos de poder e revelações religiosas". Corroborando nessa ideia, Bonnemaison (2005) afirma que "a sociedade cria-se a si mesma dentro de um espaço cultural". Assim, pode-se depreender que a comunidade estudada tem se recriado ao produzir o seu território, por meio da elaboração de novos elementos culturais, materiais ou simbólicos, que no universo pessoal e por meio da memória coletiva resignificam-se através de expressões culturais como a Feira do Troca. Esse evento constitui-se como fundamental elemento identitário e de tradições expressos como prática cultural.

As representações, materiais e imateriais, desse lugar estão atrelados ao cotidiano dos moradores como parte de suas vidas, de sua história e seguem com eles na sua compreensão e ralação com o mundo. Sendo assim, a construção da identidade local ultrapassa a noção materializada da Feira. Está na produção agrícola e na colheita que serve de base para a produção artesanal; nas ações que dão movimento e sentido de ser dos sujeitos sociais envolvidos no cotidiano que antecede a Feira (plantar, colher, decidir coletivamente, o que produzir, até a confecção dos artesanatos) na preparação do evento e na sua realização propriamente. Mas como a "própria identidade está em constante processo de construção, a forma de apropriação e de sentidos atribuídos ao evento também são múltiplos e relacionam-se ao espaço e ao tempo" (LIMA 2013, p.56).

Almeida (apud LIMA, 2013, p.54) considera o território, antes de tudo, como "uma convivialidade, uma espécie de relação social, política e simbólica que liga o homem à sua terra e, simultaneamente, estabelece sua identidade cultural". E por meio da relação da identidade social com o território "situa-se a territorialidade", que [...] "remete tanto às questões de ordem simbólico-cultural como também ao sentimento de pertencimento a um determinado território. Nesse sentido, ressalta que a cultura, como dimensão de operações simbólicas, adere às paisagens e as constrói, conformando-as mediante vivências e significações".

Segundo Claval (2008; p.17), é nas sociedades mais tradicionais que as ligações entre os grupos humanos e o espaço onde eles moram são mais diretas e mais fortes. E ao passo em que as "sociedades se modernizam, as formas de territorialidade, embora não desapareçam, tendem a sofrer mudanças" (LIMA, 2013 , p. 55). Na comunidade em análise observam-se alguns elementos, tanto simbólicos quanto materiais, que indicam mudanças na territorialidade local. Para exemplificar, cita-se o sentido da Feira e a possibilidade financeira que ela 
representa. Atualmente há muito mais produtos destinados à venda e poucos para a troca.

$E$, nas duas últimas duas versões, o evento foi coordenado e realizado pela prefeitura. Nesse ponto observa-se que a comunidade começa a perder o protagonismo, na realização da atividade. Sobre estes há aspectos discutiremos mais à frente.

\title{
Feira do Troca: a origem e as partes do evento
}

De acordo com as entrevistas realizadas e as informações disponibilizadas no site da comunidade a Feira do Troca é ocorre duas vezes ao ano, no primeiro domingo dos meses de junho e dezembro. A Feira, como expressão identitária local, possui alcance regional. Durante a realização do último evento no mês de dezembro de 2014, identificamos pessoas vieram das cidades de Brasília (DF) e dos seguintes municípios goianos: Goiânia, Abadiânia, Anápolis, Cocalzinho de Goiás, Corumbá de Goiás, Santo Antônio do Descoberto, Pirenópolis, Águas Lindas e Valparaíso.

Essa festa é construída por meio da participação da comunidade que até os dias atuais realiza a atividade como forma também de manter suas tradições e se auto afirmar para além da esfera municipal. O espaço da Feira é um local de encontro e confraternização dos moradores, entretanto, em atividade de campo realizado em razão da última Feira, em dezembro passado, observou-se a grande predominância de produtos artesanais voltados à venda em detrimento de uma menor parcela que estava destinada a troca.

Perder a condição de sede municipal para a jovem Alexânia ${ }^{5}$ é uma realidade lembrada e contada com tons de ressentimento pelos moradores mais velhos de Olhos d'Água:

\begin{abstract}
A sede do município foi roubada de Olhos d'Água em favor de Alexânia. Alex Abdallah, então prefeito, sabendo que iria ser construída uma rodovia nacional, comprou um loteamento nas margens da futura via e ali fundou a nova sede do município. E na calada da noite ele roubou a sede do município de Olhos d'Água para Alexânia [Prof. Armando; Entrevista realizada em julho/2014]
\end{abstract}

O site da comunidade informa que a mudança da capital do Brasil para o interior foi determinante para que Olhos d'Água perdesse a condição de sede municipal. Após esse evento, a cidade entrou em processo de decadência. Em referência a esse momento, dona Joaquina de Paiva diz que "as pessoas estavam muito desanimadas, sem estímulo, não faziam mais nada; era só roça”.

Embora algumas pessoas, moradores mais antigos, produzissem artesanato, que aprenderam quando criança, o ofício não era repassado aos mais jovens. Segundo dona Clotilde (conhecida como Bilu), uma das artesãs mais tradicionais da cidade "naquele tempo, do mundo velho, que não tinha nenhuma bonequinha pra brincar, nós tinha de fazer bonequinha de pano, né? Aí eu aprendi fazer de bucha (vegetal) e palha, e aos poucos foi ficando com mais qualidade". 
Desde a origem, até meados da década de 1960, a comunidade era auto suficiente em razão do "povo produzir tudo de que necessitava e só trazer de fora o sal, que vinha de Minas Gerais". Entretanto, a perda da condição de sede municipal para Alexânia trouxe alguns prejuízos à organização produtiva de Olhos d'Água. Alguns moradores venderam sua propriedade, deixaram de produzir lavoura, mudaram-se para a nova sede e lá passaram a comercializar ou realizar outra atividade econômica. Nesse cenário, os arranjos produtivos locais, até então auto suficientes às demandas de seus moradores, sofreram rupturas que contribuíram na desarticulação da economia local. Acrescente-se a esse fato 0 modo de produção agrícola da comunidade ser condicionado às estações de chuva e seca. Após as chuvas havia algumas pessoas que passavam privações pela inexistência de gêneros básicos para a alimentação.

\begin{abstract}
Tinha uma certa época, principalmente no mês de junho - que as pessoas passavam por maior dificuldade pois aqueles que trabalhavam na agricultura, não tinham o que fazer. Já tinha parado a chuva e o pessoal tinha de ficar esperando a próxima chuva para plantar de novo. Nesse intervalo, mês de junho, muita gente passava até mesmo necessidade. E a Feira veio e pegou logo... As pessoas já preparavam alguma coisa antes, pois nela já sabiam que iam fazer um dinheirinho pra 'ir segurando' até as próximas chuvas... [Sebastião Lourenço - artesão da comunidade; Entrevista realizada em abril/2015]
\end{abstract}

Nesse contexto, chegam à comunidade os professores Armando $^{6}$ e sua esposa Laís Aderne, que trabalhava com artes plásticas. Ficaram tocados pela fome e privação vivida por alguns moradores. Aos pouco ela foi ganhando a confiança da população e iniciou um trabalho coletivo voltado ao fortalecimento e resgate dos históricos saberes populares. "Dona Laís Aderne e o professor Armando procuraram resgatar o jeito de fazer artesanato de outrora. Então propôs a primeira reunião que aconteceu na escola comunitária. Começaram, então, a procurar pelas pessoas que detinham conhecimento em artesanato. Essas pessoas foram localizadas, o conhecimento foi organizado e repassado aos mais jovens, como ensino formal na escola da comunidade. Os alunos aprenderam a produção de bonecas de palha, de tecido e bucha vegetal; pintura em cerâmica, tecido e madeira; produção de esculturas e bordados; carpintaria e marcenaria. Além disso, as famílias passaram a produzir também, na agricultura, a matéria-prima utilizada na própria produção artesanal.

Desde então, o ofício da produção artesanal foi sendo repassado entre as gerações. A tecelagem, a exemplo, é um trabalho que envolve toda a família no processo de plantar, colher e fiar o algodão. As crianças são introduzidas na aprendizagem dos saberes tradicionais como parte de suas brincadeiras, tanto no descaroçamento, quanto na limpeza do algodão. O tingimento é feito com corantes naturais, tirados de plantas nativas da região.

E o que era confeccionado, ao longo de meses de trabalho, foi exposto na primeira Feira do Troca ocorrida em dezembro de 1974. O evento foi realizado em uma casa, hoje em ruínas, que se localiza em frente à praça da cidade. A Feira do 
ano seguinte cresceu bastante e ocupou o salão paroquial da igreja de Olhos d'Água.

Segundo dona Laís a Feira "proporcionou o escoamento da produção artesanal, a reprodução dos conhecimentos tradicionais e a melhoria da renda das pessoas, pois em dois períodos do ano, a cidade passou a ser visitada por muitos de turistas, que deixavam recursos na comunidade" (Arquivo: site da comunidade).

\section{A Feira como elemento de afirmação cultural}

A Feira é realizada na praça da cidade. As ruas e calçadas tornam-se estreitas para a circulação de centenas de turistas. A Feira, propriamente, acontece no domingo, embora os visitantes comecem a chegar à cidade, na sexta-feira, para participar dos festejos. Há aqueles que chegam pela manhã e vão embora ao final do dia, que são, em maioria, vindos se Brasília e de outros municípios adjacentes à Alexânia. Outros turistas hospedam-se nas poucas pousadas existentes (são apenas três) e os demais que vem para dormir, durante os três dias de realização da Feira, procuram um bom local para armar suas barracas, pois não podem ou não querem gastar com hospedagem. Segundo a população residente, há um projeto para a construção de uma área de camping, pois, a forte presença de barraqueiros, também instalados na praça, tiram o espaço de exposição dos artesãos e de circulação dos transeuntes.

Na sexta-feira, à noite, começam as apresentações de Catira com grupos folclóricos de Abadiânia, município vizinho. Segundo o site Dança Folclórica Brasileira, a Catira é uma dança genuinamente brasileira, mas não se sabe ao certo a sua verdadeira origem. Essa pode ter sido resultado da mistura de várias culturas como a africana, espanhola, indígena e portuguesa. A dança, realizada ao som de viola, é chamativa devido ao seu vigor e sincronicidade. Compõe-se de 'palmateios' e sapateios ritmados que os 'catireiros' executam, em duas fileiras - uma em frente à outra, formando pares. Ao longo das apresentações a comunidade acompanha, animada, as exibições dos grupos. Dançam, cantam e brincam ao som dos ritmos que são desenvolvidos.

Na noite do sábado ocorre a apresentação do Boi d’Água - versão local do Bumba Meu Boi. Faz-se uma roda e ao centro tem-se o Boi d'Água e mais uma dezena de pessoas mascaradas. O Boi gira e rodopia sob os incentivos e provocações dos mascarados que tentam dominá-lo. Tanto o animal quanto as pessoas estão vestidas com roupas coloridas produzidas pela comunidade. Os ritmos são cantados e tocados por artistas locais - músicos e violeiros, e falam também da história da vida de quem mora no campo. A encenação foi criada especialmente para ser apresentada nos festejos da Feira, pois representa uma expressão material que ajuda a traduzir os signos e símbolos do universo coletivo da comunidade.

Durante o domingo ocorre a Feira. No espaço da praça, são acomodados todos os tipos de mercadorias, desde os produtos artesanais, elaborados pela comunidade, aos importados e até alguns eletrônicos. Embora a diversidade, percebe-se que o artesanato ainda predomina como elemento, principalmente de venda, na maioria das barracas. Nelas encontramos artesanato de cerâmica, metal, pano, palha, pedra, metal, sementes, entre outros. Acrescente-se a estes, os produtos advindos da roça (in natura) em forma de doces, compotas ou refeições, 
que dividem espaço também com mercadorias usadas, que as pessoas levam para trocar.

O vai e vem de pessoas na Feira é muito intenso. Verifica-se a presença de visitantes das sedes municipais, do entorno de Alexânia, que se misturam aos brasilienses, aos goianienses e ao pacato morador da comunidade. Há sempre um grupo de pessoas conversando, outro tocando violão, outro apenas olhando o movimento das crianças ali próximas a brincar. A Feira é o cheiro, o som, o diverso, o movimento e as cores que a materializam. Ela se traduz nessa diversidade que é capturada e compreendida de modo diverso a partir dos referenciais contidos no universo cultural do observador.

Ao olhar do visitante desatento, que não guarda relações de pertencimento com a comunidade, talvez, a Feira pareça mais um espaço de consumo transplantando para uma área singular - a bucólica e acolhedora comunidade. Apenas um canal para o escoamento da produção artesanal local. Entretanto quando se observa nos detalhes percebe-se a importância desse evento para a integração da comunidade; como espaço de convivência; de encontro e prosa. Nela também os laços de pertencimento entre as pessoas e o lugar se fortalecem. Embora as aderências que a Feira vem ganhando, ao longo do tempo, e que podem descaracterizar a sua essência, ela ainda se constitui em singular elemento de fortalecimento comunitário.

\section{A Feira do Troca enquanto atrativo turístico}

Para Lima (2010), vivemos em um tempo em que tudo é cultural e tudo pode vir a se tornar patrimônio em virtude dos interesses políticos, particulares ou mercantis. Nesse bojo, tem-se o turismo que é uma atividade econômica de enorme capacidade de geração de receita e, dialeticamente, potencializadora de possíveis impactos negativos, dado o seu desenvolvimento. Essa atividade tem capturado, com certa facilidade, as expressões culturais locais, transformando-as em produtos mercantilizados pelo turismo e lazer. Para a autora, de modo geral, o turismo é capaz de globalizar culturas, de consolidar políticas públicas, de criar e ocupar novos espaços e lugares, de aumentar o fluxo de pessoas, serviços e mercadorias.

O mercado busca por elementos característicos e diferenciais de cada cultura; e quanto mais original, melhor matéria-prima será para a criação de um produto turístico comercializável e competitivo no âmbito internacional. Para Barretto (2000; p.48), "o legado cultural, assim transformado em produto para o consumo, perde seu significado. A cultura deixa de ser importante por si mesma e passa a ser importante por suas implicações econômicas".

Assim, o turismo se coloca como uma atividade econômica nova que se apropria do espaço por meio do estabelecimento de ações que assegurem a visibilidade e a valorização desses lugares através do desenvolvimento de um conjunto de ações e práticas então adequadas e mercantilizadas para apropriação turística.

Em Olhos d'Água durante os três dias em que ocorre a Feira o ambiente é preparado para receber e atender grande demanda por hospedagem, alimentação, estacionamento de carros, áreas de circulação de pessoas e comercialização de produtos. A população local soma um total de 1.445 pessoas, mas nos três dias de festejos tem-se cerca de 5 mil pessoas circulando pela comunidade. $O$ trânsito nas 
ruas estreitas fica completamente congestionado sem alternativa de fluidez. Esse contingente demográfico quebra com o silêncio e tranquilidade da pacata comunidade. Embora alguns moradores não se incomodem com a movimentação e vejam esse momento como uma oportunidade de ganhar algum dinheiro outros acham que a Feira atrapalha e perdeu o sentido.

O turismo realizado no distrito de Olhos d'Água ainda é muito incipiente em referência às iniciativas do poder público municipal para o desenvolvimento da atividade. O poder público local destaca a Feira do Troca como uma festa tradicional que esbanja arte e cultura sendo esse um momento de encontro, diversão e compra.

Serpa (apud LIMA, 2013; p. 59), ao tratar sobre o conceito de "espetacularização", analisa alguns casos no estado da Bahia que apontam para esse fenômeno, nos quais ocorre o nascimento da cidade da "festa-mercadoria". Nela, a história e a tradição dos lugares são industrializados, há requalificações e revitalizações urbanas e, ainda, a inserção no mercado globalizado das imagens turísticas e dos lugares-espetáculo.

Em Olhos d'Água, não obstante a crescente visitação turística, ainda não possuem relevo as ações do poder público na requalificação urbana, voltadas à exploração turística. E a comunidade segue com o traçado e peculiaridades originais. Hoje, há uma forte divulgação da atividade que é realizada pela própria comunidade e, mais frequentemente, por um grupo de artistas e donos de pequenas pousadas e restaurantes que atraídos pela beleza e tranquilidade passaram a morar e montar o próprio negócio na comunidade. Esse grupo vê os festejos da Feira como uma boa oportunidade de escoamento dos seus produtos.

\section{Ainda sem concluir}

Já se passaram quarenta anos desde a realização da primeira Feira. No transcorrer do tempo novos elementos foram introduzidos na composição da atividade como reflexo das mudanças incorporadas ao modo de vida local. Uma das mudanças refere-se ao aumento da quantidade de produtos disponíveis para a venda em detrimento daqueles voltados à troca. Os primeiros são principalmente de origem artesanal e pela singularidade, logo despertam o interesse do turista que deseja a sua aquisição, mediante pagamento em dinheiro. A reclamação recorrente, dos turistas que visitam, anualmente, a Feira é a crescente escassez de produtos artesanais voltados à troca. $\mathrm{Na}$ atividade de campo realizada em dezembro passado, foi observado que vem crescendo a disponibilidade de produtos voltados à venda, em detrimento da quantidade daqueles destinado a troca. Diante disso, pergunta-se: a afirmação da dona Nair, moradora local, que diz ser a Feira o local onde o "da roça é trocado pelo da cidade", na prática ainda se realiza?

O inegável é que a Feira do Troca, ao longo dos anos, também recebeu as influências geradas pela mercantilização capitalista. E mesmo a população original que prepara e vivencia o evento, e os processos a ele inerentes, vê esse momento como uma oportunidade ímpar de ganhar algum dinheiro.

Por outro lado, é explícito que o visitante é bem acolhido pela cidade e seus moradores. Destacam-se as expressões culturais materiais que a torna singular: a localização em um vale com vegetação e água em abundância; a arquitetura, as 
cores e a disposição das edificações; os pomares e jardins que estão sempre acrescidos de um detalhe brejeiro. A este ar bucólico tem-se ainda os signos e significados imateriais que a cada momento orienta as práticas do fazer individual e coletivo da comunidade que encontra em seu espaço vivido a inspiração para a realização das diversas expressões culturais ali realizadas.

Diante do exposto fica o seguinte questionamento: está se perdendo o sentimento de que o espaço da Feira também é estratégico para o fortalecimento da identidade local da comunidade? ${ }^{7}$

\section{Referências bibliográficas}

ARAÚJO SOBRINHO, F.L. Turismo e dinâmica territorial no eixo Brasília-Goiânia. 2008. 447 f. Tese (Doutorado em Geografia) - Programa de Pós-Graduação em Geografia, Universidade Federal de Uberlândia, Uberlândia, 2008.

BEZERRA, A.C.A. Cidade, Cultura e Planejamento em Tempo de Espetáculo. In: Encontro Nacional da ANPEGE, 7, Niterói. Anais... Niterói: 2007a.

BONNEMAISON, J. Culture and Space: conceiving a new Culture Geography. I. B. Tauris. London, New York, 2005.

CLAVAL, P. Campo e perspectivas da Geografia Cultural. In. CORRÊA, R. L.; ROSENDAHL, Z. Geografia Cultural: Um Século. Rio de Janeiro, Editora UERJ, 2002, p. 132 a 196.

CLAVAL, P. Uma, ou algumas, abordagem(ns) cultural(is) na geografia humana. In: SERPA, A. (org.). Espaços culturais: vivências, imaginações e representações. Salvador: EDUFBA, 2008. p. $15-29$.

IBGE, Diretoria de Pesquisas, Coordenação de População e Indicadores Sociais. Disponível em: $<$ http://www.cidades.ibge.gov.br/xtras/perfil.php?lang $=\&$ codmun $=520030>$. Acesso em: 14 fev. 2015.

LIMA, L.N.M. A apropriação da cultura pelo turismo, a revalorização e a ressignificação das identidades culturais. GEOgraphia, UFF, Rio de Janeiro, V. 12, N. 24, 2010, pp. $150 \quad$ - 166. Disponível em: <http://www.uff.br/geographia/ojs/index.php/geographia/article/view/387/306>.

Acesso em: 10 nov. 2014.

LIMA, L.N.M. O turismo, a reinvenção e a espetacularização na Procissão do Fogaréu da Cidade de Goiás (GO). Revista Brasileira de Ecoturismo, São Paulo, v.6, n.1, jan/abr-2013, pp.53-64. Disponível em: $<$ http://www.sbecotur.org.br/rbecotur/seer/index.php/ecoturismo/article/view/390>. Acesso em: 12 nov. 2014.

PREFEITURA DE ALEXÂNIA. Disponível em: <http://www.alexania.go.gov.br>. Acesso em 13 fev. 2015.

SERPA, A. O espaço público na cidade contemporânea. São Paulo: Contexto, 2007. Serviço Brasileiro de Apoio às Micro e Pequenas Empresas - SEBRAE. Disponível em: <http://www.sebraego.com.br>. Acesso em 20 nov. 20141.

SITE: <http://catira-dancafolcloricabrasileira.blogspot.com.br/>

SITE: <http://olhodogoias.blogspot.com.br/2009/02/primeira-casa.html>. 


\section{Notas}

1 Segundo Araújo Sobrinho essa porção "compreende as duas maiores metrópoles da Região Centro-Oeste do Brasil e os municípios de sua área de influência. Esse Eixo apresenta características naturais e socioeconômicas bem diversas, porém a sua posição geográfica e a análise das transformações recentes em sua estrutura urbano-regional permitem considerar essa região como uma das mais dinâmicas nas últimas décadas no Brasil". E a consolidação desse Eixo é explicada, dentre outros fatores, pelas "facilidades de transporte, a infraestrutura, o agronegócio, o significativo mercado consumidor e a centralização do poder" (2008, p. 80).

2 Disponível em: http://olhodogoias.blogspot.com.br/2009/02/primeira-casa.html. (Acesso em: 15 set. 2014).

${ }^{3}$ Informação obtida junto ao professor Armando; docente aposentado da UnB e morador de Olhos d'Água desde 1963. (julho/2014).

${ }^{4}$ Terra argilosa usada para fazer tijolos crus e rebocos; 2 . Tijolo grande desse barro, seco ao sol; tijolo cru [...]; 3. Seixo arredondado que se encontra no leito dos rios (Dicionário Michaelis).

${ }^{5}$ O Eixo Brasília-Goiânia possui papel determinante na forte dinâmica do município de Alexânia. O citado município possui localização em uma posição privilegiada, 120,9 km da capital do estado e a 92,4 km de Brasília, tem sua gênese marcada pela origem da citada rodovia. O então prefeito, Alex Abdalah, ao "tomar conhecimento de que, a $12 \mathrm{~km}$ de distância de Olhos d'Água, comunidade originária do atual município, iria passar uma estrada ligando a capital do estado à Brasília, providenciou a compra de um terreno às margens da futura rodovia. Em seguida, loteou a área, prosseguiu com a doação e venda das terras, construiu a prefeitura e apoiou a execução de estruturas urbanas, dando origem a futura sede do município" (Prof. Armando, morador de Olhos d'Água - Alexânia, 2014).

6 O casal havia comprado um terreno onde pretendiam construir uma casa para descansar nos finais de semana.

7 O presente artigo foi elaborado no âmbito da pesquisa de doutorado que ora se desenvolve no curso de Geografia da Universidade de Brasília e tem o apoio financeiro da CAPES. O artigo original foi apresentado durante o "VI Coloquio Internacional Ciudades del Turismo: Gestionar, viajar y otras formas de apropiación patrimonial", ocorrido em junho de 2015 na Facultad de Arquitectura de la UNAM, Ciudad de Mexico. Entretanto, a versão aqui publicada está acrescida de novas considerações, resultantes dos debates ocorridos durante o Simpósio e da continuação dos trabalhos da pesquisa em campo.

Edilene Américo Silva: Universidade de Brasília, Brasília, DF, Brasil.

E-mail: edileneamerico@hotmail.com

Link para o currículo Lattes: http://lattes.cnpq.br/9352275250506883

Data de submissão: 11 de agosto de 2015

Data de recebimento de correções: 15 de março de 2016

Data do aceite: 15 de março de 2016

Avaliado anonimamente 